\title{
PERCEPTION, EVIDENCE, AND OUR EXPRESSIVE KNOWLEDGE OF OTHERS’ MINDS
}

\author{
Anil Gomes \\ Trinity College, University of Oxford \\ To appear in a volume on the problem of other minds, edited by $\mathrm{M}$. \\ Parrott \& A. Avramides, forthcoming with OUP [submitted 2017]
}

\begin{abstract}
'How, then, she had asked herself, did one know one thing or another thing about people, sealed as they were?' So asks Lily Briscoe in To the Lighthouse. It is this question, rather than any concern about pretence or deception, which forms the basis for the philosophical problem of other minds. Responses to this problem have tended to cluster around two solutions: either we know others' minds through perception; or we know others' minds through a form of inference. In the first part of this paper I argue that this debate is best understood as concerning the question of whether our knowledge of others' minds is based on perception or based on evidence. In the second part of the paper I suggest that our ordinary ways of thinking take our knowledge of others' minds to be both non-evidential and nonperceptual. A satisfactory resolution to the philosophical problem of other minds thus requires us to take seriously the idea that we have a way of knowing about others' minds which is both non-evidential and nonperceptual. I suggest that our knowledge of others' minds which is based on their expressions - our expressive knowledge - may fit this bill.
\end{abstract}

\section{Lily's Question}

There's a lovely image in Virginia Woolf's To the Lighthouse which captures the isolation from other people that all of us, at one time or another, can feel. Lily Briscoe is reflecting on her inability to get into the secret chambers of another's heart: 
How, then, she had asked herself, did one know one thing or another thing about people, sealed as they were? Only like a bee, drawn by some sweetness or sharpness in the air intangible to touch or taste, one haunted the dome-shaped hive, ranged the wastes of the air over the countries of the world alone, and then haunted the hives with their murmurs and their stirrings; the hives, which were people. (Virginia Woolf, To the Lighthouse, pp.57-58)

In this striking passage, people are presented as hives, able to attract and repel others through signals which emerge from their surface, but incapable of ever truly being known.

It's not hard to get oneself into a frame of mind where this can seem like the human condition. ${ }^{1}$ Other people are a mystery and the epistemic isolation which worries Lily can seem to reflect our position in a world of others separate from ourselves. Scepticism about our knowledge of other people's mental lives - unlike, perhaps, scepticism about the external world - gains a foothold in our everyday interaction with others. ${ }^{2}$

But such scepticism is revisionary and it is counteracted by the extent to which we take ourselves to know the most basic and mundane truths about the mentality of those around us. ${ }^{3}$ Arun hopes for a Labour victory; Amit thinks he can't be seen; Hauwa is frustrated with Nitya's prose. We know these things and the fact that we know them plays a central part in our relationships with one another. This raises a puzzle: how are we to reconcile these two aspects of our relationships with others - the centrality of our knowledge of others' minds in everyday interactions and the difficulty we have in answering Lily's question about how we know?

Philosophical discussion of this topic has often gone under the heading 'The Problem of Other Minds'. But it is important to distinguish different

\footnotetext{
${ }^{1}$ An extreme manifestation of this tendency is 'the assertion, widespread in the societies of the Pacific, that it is impossible or at least extremely difficult to know what other people think and feel' [Robbins and Rumsey 2008, p.402-3]. For more on these cultures, and the ways in which their social and interpersonal relations are structured by this belief, see the essays and commentaries in [Robbins and Rumsey 2008].

${ }^{2}$ This is one of Cavell's claims [Cavell 1979, Part Four], though disputed by Marie McGinn [1998]. That there is something unliveable about external world scepticism is a familiar thought, expressed most simply by Hume.

${ }^{3}$ This is perhaps one of the intended lessons of To the Lighthouse. See Nussbaum's reflections on knowledge of other minds in the book: [Nussbaum 1995].
} 
questions which might be raised under that title. One common way to raise a sceptical problem about others' minds is by appeal to cases of pretence and deception. Isn't is possible that those around us are merely pretending to want a Labour victory, whilst secretly intending to vote for the Tories? Or worse! - isn't it possible that they are zombies or robots, simulating desire and frustration but with nothing mental going on at all? The Problem of Error claims that our inability to rule out such scenarios entails our possessing no knowledge of others' minds.

There is certainly an issue about our knowledge of others' minds here. But it doesn't turn on anything distinctive about our relationship to others' minds. Similar sceptical scenarios arise for perceptual knowledge - isn't it possible that you're hallucinating right now? - and memorial knowledge isn't it possible that the world sprang into existence only five minutes ago, with all your seeming memories included? And responses to the problem as it arises in any one of these areas can be transferred over to the others. The Problem of Error is a general sceptical problem which can have application when thinking about our knowledge of others but which raises no issues specific to that particular case. ${ }^{4}$

Contrast the question that Lily Briscoe asks herself: how does one know one thing or another about other people? This is not a worry about pretence or deception: the question arises without any concern from Lily that she is being deceived. Rather, it is a question about the source of our knowledge of others' minds. How do we know about others' minds? And - if we can't identify a source - do we know?

I've suggested elsewhere that this Problem of Sources has better claim to being the problem of other minds - both philosophically and historically. ${ }^{5}$ We can formulate it as an antinomy of three claims:

\footnotetext{
${ }^{4}$ See [Gomes forthcoming, \$2] for further commentary on this form of the problem of other minds. [McDowell 1982] is a nice example of someone who sets up the issue in terms of pretence, and then immediately draws a general moral about knowledge.

${ }^{5}$ [Gomes forthcoming, \$3]. This is certainly the way in which the problem was raised in the first half of the twentieth-century; it's also central to the discussions of William Hamilton, J.S. Mill and others. See, for example, [Mill Hamilton, Works, Vol. IX, pp.190-191] and the discussion in [Thomas 2001]. Concerns about the possibility of pretence seem to originate with Wittgenstein's comments in his writings on the
} 
(1): If you know that $p$, then there is a means by which you know that $p$.

(2): There is no means by which one can know truths about another's mind.

(3): We know truths about another's mind.

(1) has seemed to many to be close to a conceptual truth - or, for those who are sceptical of such things, at least a basic and obvious one. ${ }^{6}$ And (3) is just the denial of scepticism. So avoiding scepticism requires us to deny (2) which returns us to Lily's question: how do we know truths about another's mind?

Two broad answers can be found in the history of thinking about this question. Thomas Reid [1785] tells us that we know about others' minds 'by a kind of natural perception similar to the perceptions of sense'; Mill [1865] objects that the way in which we know about others' minds is rather 'exactly parallel to that by which Newton proved that the force which keeps the planets in their orbits is identical with that by which an apple falls to the ground'. Nathalie Duddington [1918] tells us that 'our knowledge of other minds is as direct and immediate as our knowledge of physical things', that 'there is no inherent absurdity in saying that minds can be perceived'; Price [1938] counters that our knowledge is based only on 'the perceiving and understanding of noises and other symbols which gives one evidence for the existence of other minds'. These authors present us with two options for answering Lily's question: we know others' minds through inference; or we know others' minds through perception.

philosophy of psychology [1992]; this is the context for McDowell's discussion and many other contributions from that period.

${ }^{6}$ Consider Austin's claim, endorsed by Williamson [2000, pp.252-3], that whenever someone makes a claim to knowledge, it is appropriate to ask 'How do you know?'. This linguistic fact about the appropriateness of a certain question reflects a metaphysical fact about knowledge: namely, that if someone knows that $\mathrm{p}$, then there is a means by which she knows it. Some readers of Wittgenstein have denied the claim for the case of selfknowledge - for instance, Hampshire [1969, pp.282-283] and Davidson [1991, p.212] but their reasons are particular to that case.

${ }^{7}$ [Reid, Essays on the Intellectual Powers of Man, VI, ch.5]; [Mill, Hamilton, Works, Vol. IX pp. 190-191]; [Duddington 1918, p.147, p.156], [Price 1938, p.438]. Nathalie Duddington was a student of Dawes Hicks at UCL. She is remembered now, if at all, for her translations of Russian literature but her two essays on our knowledge of others' minds are wonderful in both style and substance. 
These two options - inference and perception - continue to frame contemporary debates about our knowledge of others' minds. ${ }^{8}$ Recent work in the social cognition literature, for instance, has been dominated by the questions of whether it is possible to perceive the mental states of another person, and what role such perception might have in our coming to know about others' minds. Those who defend perceptual accounts contrast them with accounts of social cognition which take us to infer the existence of psychological states. Participants on both sides of the debate often present perception and inference as the only options for explaining our knowledge of others' minds. ${ }^{9}$

\section{Two Assumptions}

This way of framing the problem of other minds makes two assumptions. First, of generality: each of these options can seem to assume that there is one particular way - or, perhaps, some fundamental way - by which we come to know others' minds. But why we should make that assumption? There may be no general way by which we come to know about the minds of others. Second, of distinction: the debate seems to assume that perception and inference are to be distinguished. But how should we make that distinction? Let me take these in turn.

Generality: we can draw a distinction between two different ways of grouping known facts: on the basis that such knowledge has been gained from the same source, or on the basis that it all concerns the same domain. Call these two ways of classifying knowledge source-knowledge and domainknowledge respectively. Some examples of source-knowledge include: the facts I know on the basis of perception; the facts that you know on the basis of reading Wikipedia; the facts which Priya knows through divine revelation. Some examples of domain-knowledge include: everything I know about cars; that which you know about Sri Lanka; the things you know about the Catholic Church.

The difference between these two ways of classifying known facts is not always made clear, as when philosophers move interchangeably between discussing perceptual knowledge and knowledge of the external world. But

\footnotetext{
${ }^{8}$ See [Michael and De Bruin 2015] as a representative instance.

${ }^{9}$ Examples on the perceptual side include [McDowell 1982], [Cassam 2007], [Gallagher and Zahavi 2008], [Smith 2010], [Krueger and Overgaard 2012], [McNeill 2012]. Their opponents include [Gopnik and Wellman 1992] and [Nichols and Stich 2003].
} 
we should be careful to mark the distinction, for it need not be the case that some knowledge picked out via a certain domain has all arisen from the same source. And, indeed, although there are cases where all the things we know about a particular domain were gained from the same source - 'everything I learned about love I learned from romance novels' - this is the exception rather than the norm. Given that knowledge of others' minds is a type of knowledge picked out via its domain, we have no grounds for thinking that it is all gained via the same source. So why should we acquiesce in the assumption that our knowledge of others' minds is either perceptual or inferential, as opposed to some mix of the two (and, perhaps, others). ${ }^{10}$

Indeed, it should be common ground to all parties to this debate that some of our knowledge of others' minds involves processes of inference. We sometimes puzzle over another's strange behaviour - why did she behave so badly at dinner? - before concluding that it is explained by some fact about her mental life - she must be jealous of Adanna's new partner. So everyone should agree that some of our knowledge of others' minds results from inference.

How, then, should we characterise the debate? Participants to the debate often take there to be some class of disputed cases under consideration. These are often introduced by example - we are instructed to consider a case in which you are face to face with another, see her smile and come to believe that she is happy - and it is not clear what principles delimit the relevant class of cases. At a first pass, we can think of the class of disputed cases to be ones in which we are in the presence of another person and come to know what she thinks or feels without going through any explicit process of inferential reasoning. ${ }^{11}$ I think there are substantive questions one might raise about whether this kind of procedure is sufficient for picking out the disputed class, but let me put those to one side. In what follows I will take it that the debate concerns only a disputed class, picked out unproblematically, and that there are definite examples of inferentially acquired knowledge of others' minds outside that class. (Another way to put the point: I will take the debate to be one about whether all of our knowledge of others' minds is inferential, given that some is.)

\footnotetext{
${ }^{10}$ See [Gomes forthcoming, \$5] for a brief discussion of this issue in relation to standard presentations of the problem of other minds.

${ }^{11}$ See [McNeill 2012, p.576] and [Smith 2013, p.1] for explicit restrictions of this sort.
} 
Distinction: in order for this debate to be substantive, there needs to be some interesting epistemological distinction between perception and inference otherwise it's hard to see what would turn on the answer to the question. Consider a debate about whether we know others' minds through processes of inferential reasoning undertaken on a weekday or through processes of inferential reasoning undertaken at the weekend. I suppose it would be interesting to find out that only one or other of those were true - but it doesn't seem like anything of epistemological significance would turn on the answer. When one thinks about the reasons why those processes count as knowledge-generating mechanisms, there is no difference between processes of inferential reasoning undertaken on a weekday and processes of inferential reasoning undertaken at the weekend and thus no reason to distinguish them when thinking about the capacities which allow us knowledge.

How should we distinguish knowledge gained on the basis of perception from knowledge gained on the basis of inference? There are multiple ways of drawing the contrast, and one might worry that a lack of clarity on this issue undermines much of the debate. Consider inference. At its weakest, one might think of any episode of psychological processing which can be modelled in inferential terms as an instance of inference. At its strongest, one might require inference to involve explicit processes of conscious and deliberative inferential reasoning. And there are various notions in between: episodes of psychological processing which can be modelled in inferential terms and take propositional states as inputs; episodes of psychological processing which can be modelled in inferential terms and take nonperceptual propositional states as inputs; episodes of psychological processing which can be modelled by an epistemically virtuous theory; and so on. These different notions of inference determine different ways of drawing the distinction between perceptual and inferential knowledge.

One suspicion about some of the recent debate is that its proponents are working with different notions of inference, and thus failing to engage with one another. ${ }^{12}$ Some of the defenders of a perceptual account, for instance, argue against the claim that our knowledge of others' minds is inferential by noting that we don't seem to engage in any conscious processes of inference in coming to know what another person thinks or feels. But the lack of any conscious process of inference is compatible with there being episodes of psychological processing which can be modelled in inferential terms.

\footnotetext{
${ }^{12}$ See [Spaulding 2015, p.476] and [McNeill 2015a, \$2] for a recognition of this point.
} 
Correspondingly, some of the defenders of an inferential account claim that the presence of such processes is enough to show that our knowledge of others' minds is inferential. But many of the processes involved in perception may be modelled in inferential terms, so the presence of such processes won't suffice to show that this knowledge is inferential rather than perceptual. ${ }^{13}$

I think the right thing to conclude is that there is no one way of drawing a distinction between perceptual and inferential knowledge and that different ways of drawing the distinction will have differing implications for this debate. The important point is that we need a way of drawing a distinction which makes clear the significance of asking whether our knowledge of others' minds is perceptual or inferential.

\section{Evidence \& Proof}

Here is a suggestion. Note that many of those involved in this debate move freely between the claim that our knowledge of others' minds is based on inference and the claim that our knowledge of others' minds is based on evidence. ${ }^{14}$ The thought here is that our knowledge of others' minds is inferential because it is based on the evidence of how other people behave. Call this an evidential construal of our knowledge of others' minds: our knowledge of others' minds is based on evidence.

How does knowledge based on evidence compare with knowledge based on perception? J.L. Austin counsels against our taking perceptual knowledge to be based on evidence in a famous passage from Sense and Sensibilia:

The situation in which I would properly be said to have evidence for the statement that some animal is a pig is that, for example, in which the beast itself is not actually on view, but I can see plenty of pig-like marks on the ground outside its retreat. If I find a few buckets of pig-food, that's a bit more evidence, and the noises and the smell may provide better evidence still. But if the animal then emerges and stands there plainly in view, there is no longer a question of collecting evidence; its coming into

\footnotetext{
${ }^{13}$ [Spaulding 2015] contains an excellent discussion of some of the issues which arise here; see [Hatfield 2002] for a discussion of the history and prospects of explaining perception in terms of unconscious inferences.

${ }^{14}$ For example, [Price 1938]. Compare Paul Boghossian who moves from our having to 'infer what [people] think from observations about what they do or say' to the claim that such knowledge is based on 'supplementary evidence' [1989, p.7]
} 
view doesn't provide me with more evidence that it's a pig, I can now just see that it is, the question is settled. [Austin 1962, p.115]

Many in our more enlightened, post-Gricean, times will balk at Austin's move from what is not properly said to what is false. But put these concerns to one side. If Austin is right, then knowledge which is based on perception is not knowledge which is based on evidence.

How should we understand Austin's contrast between evidence and perception? The central claim is that evidence falls short of that which it purports to establish, whereas perception settles the question. This way of thinking about evidence and perception was central to the Oxford Realist tradition in which Austin was taught. ${ }^{15}$ We can gloss the distinction as follows: when a subject has evidence for the claim that $\mathrm{p}$, she has something which is compatible with it not being the case that p. But when a subject has proof - and perception can be a form of proof - then she has something which excludes the possibility of $\mathrm{p}$ not being so. Other ways of making this distinction might appeal to the contrast between defeasible and indefeasible warrant for judgements, or that between inconclusive and conclusive grounds. Austin's thought is that evidence provides defeasible warrant for judgements whilst perception provides conclusive grounds. ${ }^{16}$

I have spoken here about knowledge based on evidence, and knowledge based on perception. But that is to interlope upon Austin's conception. For Austin thinks that knowledge requires proof; evidence alone can get you, at best, a justified belief - but this falls short of knowledge. This stance is shared by those who think that knowledge requires conclusive grounds, since Austin's conception of evidence has it that evidence can provide nothing more than inconclusive grounds for belief. I won't dwell on this obtrusion. Those who wish to retain the term 'knowledge' for that which is provided by proof can

\footnotetext{
${ }^{15}$ See [Kalderon and Travis 2013] on Oxford Realism. Charles Travis makes much of this notion of evidence, and its contrast with proof: see his especially his [2005].

${ }^{16}$ This modal gloss on the distinction between evidence and proof is suggested by Austin's discussion, but it raises a number of difficulties. First, it needs finessing to allow the possibility of our knowing necessary truths on the basis of evidence despite the fact that in such cases our grounds are not compatible with the falsity of what we know. Second, it needs to say something about evidence which is metaphysically or nomologically incompatible with that which is known: do such grounds settle the question or fall short? I will put these issues to one side since those who have taken our knowledge of others' minds to be based on evidence assume that in such cases we know a contingent truth on the basis of evidence which falls short in the way indicated by Austin.
} 
recast the debate as one about whether we ever have perceptual knowledge of others' minds or whether the most we can obtain is a belief justified by evidence. What is important is that there are two different epistemic states one can be in concerning the proposition p: one in which one's grounds are compatible with it not being the case that $\mathrm{p}$; and one in which one's grounds exclude the possibility of $\mathrm{p}$ not being so. And the question is into which camp our beliefs about others' minds fall. ${ }^{17}$

I take this distinction between evidence and proof to be largely stipulative. ${ }^{18}$ But many will wonder whether it aligns with the distinction between inference and perception. Note, for example, that if knowledge based on inference is to be equated with knowledge based on evidence, then we need distinguish between inductive and deductive inference, since in cases of deduction one has grounds for $\mathrm{p}$ which are incompatible with the falsity of p. (Deduction is, thus, a form of proof.) In what follows I will use 'infer' and its cognates for the case of inductive inference, and 'deduce' and its cognates for the case of deductive inference. So precisified, the alignment of evidence and inference looks plausible.

But few will agree with Austin that perception can be a form of proof. For the dominant way of thinking about perception in contemporary philosophy - perhaps in western philosophy as a whole - has it that perception falls short in the way that evidence falls short. Perception falls short because one could have the same run of experience in very different worlds. And if that is the case, then perceptual experience can at most provide a subject with evidence for her beliefs about the world, since her perceptual experiences are compatible with the falsity of what she believes on their basis.

Austin, of course, may wish to deny this, as a number of those writing after him went on to do. ${ }^{19}$ And for those who deny that perceptual knowledge is based on evidence, there is an important epistemological contrast between

\footnotetext{
${ }^{17}$ I'm here following the lead of Duddington who expresses reservations about calling that which is gained on the basis of evidence 'knowledge', for reasons of a piece with those adduced by the Oxford realists, before putting them to one side on the grounds that the nomenclature doesn't matter so long as one recognises the difference in epistemic basis between the two cases. See her [1918, p.153].

${ }^{18}$ See [Kelly 2014], [Hacking 1975, p.37] for some evidence that Austin's account fits our ordinary conception of evidence.

19 These include [Hinton 1973], [McDowell 1982], [Martin 2002], [Travis 2013] amongst others.
} 
knowledge which is based on evidence and knowledge which is based on perception. Knowledge which is based on evidence is knowledge which is based on something which is compatible with things not being as the subject takes them to be. Knowledge which is based on perception is knowledge which is based on something which is not so compatible. This distinction is epistemologically significant.

The distinction between evidence and proof thus gives us one way to mark a distinction between knowledge based on perception and knowledge based on inference, a way which explains why the distinction is epistemically significant. Moreover, it is a way of marking the distinction which is accurate to the history of this debate. For many of those who have defended perceptual accounts of our knowledge of others' minds also endorse nonevidential accounts of perception: accounts on which coming to know that $\mathrm{p}$ on the basis of perception involves a subject knowing that $\mathrm{p}$ on the basis of something which is incompatible with the falsity of $\mathrm{p}$. And for these writers, the contrast to be drawn between knowledge which is based on evidence and knowledge which is based on proof makes the question of whether our knowledge of others' minds is perceptual or inferential a significant one.

Some examples. Thomas Reid rejects accounts of perception on which our knowledge of the material world is mediated by sensations which fall short of establishing truths about the material world (Inquiry $\mathrm{V}$ vii-viii) in favour of an account on which we perceive material objects immediately (Essays on the Intellectual Powers of Man II vii, p.86) ${ }^{20}$ Nathalie Duddington holds that, in cases of perception, 'the mind is in the presence of the object', whereas 'the process of inference whereby we are led to suppose that [some things] exist does not take us right up to them, but leaves us half-way, merely indicating the direction in which they lie' [1918, p.52]. And John McDowell has repeatedly counselled against us taking perception as falling short of the facts [1982, p.386]. Each of these writers takes the question of whether our knowledge of others' minds is perceptual or inferential to be a significant one. And each holds that inference, unlike perception, falls short of establishing that which is known.

\footnotetext{
${ }^{20}$ I beg a number of questions here about the correct interpretation of Reid's account of perception. See [Buras 2002] and the papers referenced in $n .1$ of his paper for some of the interpretative issues at stake.
} 
This is not to rule out other ways of drawing a distinction between knowledge based on perception and knowledge based on inference. It may be that those who think of perception as defeasible can draw epistemically significant distinctions within the class of defeasible sources of knowledge, such that the question of whether our knowledge of others' minds is perceptual or inferential retains force. ${ }^{21}$ But the contrast between evidence and proof provides one way of drawing the distinction, a way which is true to the history of the debate.

In what follows I will replace the question of whether our knowledge of others' minds is based on inference or perception, with the question of whether our knowledge of others' minds is based on evidence or perception, where perception is understood as a form of proof. So replaced, and with Austin's distinction in place, the question of whether our knowledge of minds is perceptual or inferential amounts to the question of whether our knowledge of others' minds is based on evidence which falls short of that which is known, or whether it is based on a perceptual experience which is incompatible with the falsity of what is known.

\section{Symptoms \& Signs}

Let us return to the puzzle I noted at the start of this essay: that of reconciling the centrality of our knowledge of others' minds in everyday interaction with the difficulty we have in answering Lily's question about how we know. It is striking that the alternatives of evidence and perception dominate the debate about the source of our knowledge of others' minds, as if they exhausted the possible options for answering Lily's question. I want to explore ways in which the foreclosure of other options stymies the hope of our finding a resolution to this debate and explains the difficulties we have in answering the question "How do we know?". ${ }^{22}$

\footnotetext{
${ }^{21}$ Perhaps. But I suspect that at least part of the reason for the relative lack of interest in the problem of other minds in contemporary epistemology is the assumption that both perception and inference provide defeasible support for beliefs and that nothing of much consequence turns on the question of whether our knowledge of others' minds is defeasibly grounded in perceptual states or whether it is defeasibly grounded in nonperceptual states via inference. See [Gomes 2011, pp.353-355] for discussion of some other reasons.

${ }^{22}$ One issue, which I won't explore here, concerns the exclusion of testimony from these debates. For a discussion of the role of testimony in explaining our knowledge of others' minds, see [Gomes 2014].
} 
Consider the following three claims, restricted to the class of disputed cases:

1. Our knowledge of others' minds is non-evidential.

2. Our knowledge of others' minds is non-perceptual.

3. Our knowledge of others' minds is either evidential or perceptual.

These three claims are incompatible. If our ordinary ways of thinking about our knowledge of others' minds committed us to all three, then our common-sense conception of the way in which we know the minds of others would be incoherent. If it is incoherent, then it is no surprise that we find answering Lily's question so difficult.

There is some evidence that the first two claims are part of our ordinary ways of thinking. At least, I will consider the case for claiming so below. But the third claim is no part of common-sense. It is a philosophical claim, one which is brought to bear on our ordinary ways of thinking. Someone who holds onto the third claim will find our ordinary conception incoherent, at least so long as common-sense endorses the first and second claim. And that will motivate them to deny either the first or second claim. But, in doing so, they are committed to denying one aspect of our ordinary conception of such knowledge. Extant perceptual and evidential views are, to this extent, error theories, revisionary of our ordinary ways of thinking.

If the third claim is not part of common-sense, then our ordinary ways of thinking can be cleared of incoherence. But there remains confusion. For how could there be a way of knowing about empirical facts which is both non-evidential and non-perceptual? Mathematical reasoning is both nonevidential and non-perceptual; indeed, it is the domain where the notion of proof is most at home. ${ }^{23}$ But it is hard to see how we could use such a way of knowing to gain knowledge of others' minds. So what else could there be? It is the difficulty we have in answering this question which, I suggest, accounts for the difficulty we have in answering Lily's question. We don't take our knowledge of others' minds to be perceptual; nor do we take it to be evidential. The difficulty in answering Lily's question arises from the fact that there is a gap at the heart of our common-sense thinking about

\footnotetext{
${ }^{23}$ It is here that the Oxford Realist notion of knowledge as proof seemed to them to be most secure [Prichard 1919, p.302].
} 
knowledge of others' minds. The common-sense picture is not incoherent. But it is waiting to be filled in.

This diagnosis of the problems involved in answering Lily's question will convince only if it can be made plausible that the first and second claim are part of our common-sense conception. And how might one defend those claims? Consider first whether (1) is part of common-sense. Austin takes up this question at the end of his paper 'Other Minds' [1946]. He conducts his discussion in terms of a distinction between the symptoms of mental phenomena and the phenomena themselves. ${ }^{24}$ Symptoms of mental phenomena are evidence of mental phenomena: something distinct from the mental phenomenon which point towards it, but falls short of conclusively establishing it. '[W]e never talk of 'symptoms' or 'signs' except by way of implied contrast with inspection of the item itself... The words function like such words as 'traces' or 'clues'.' [p.105, his emphasis]. So those who take our knowledge of others' minds to be based on symptoms take it to be based on evidence.

Knowledge of others' minds which is based on evidence or symptoms is knowledge which is mediated by something which falls short of establishing truths about another's mental lives. Do we think of our knowledge of others' minds in this way? Austin writes:

\footnotetext{
[I]s this the way we do talk? Surely we do not consider that we are never aware of more that symptoms of anger in another man? 'Symptoms' or 'signs' of anger tend to mean signs of rising or of suppressed anger. Once the man has exploded, we talk of something different - of an expression or manifestation or display of anger, of an exhibition of temper, and so forth. [p.107]
}

The claim here is that we do not ordinarily conceive of mental phenomena as standing to their expressions, manifestations, and displays as a disease stands to its symptoms.

We can put this in terms of evidence. If we thought of our knowledge of others' minds as based on evidence, we would have to think of the relation between mental phenomena and their expression as primarily evidential. This is the way we think of the relation between mental phenomena and ${ }^{24}$ This is a distinction which Wisdom uses in his contribution to the symposium in
which Austin's paper features [1946, p.131f]. 
some of what people say and do: the twitch of an eyebrow provides evidence that someone is trying to keep her anger in check, say [Austin 1946, p.107]. But once she has exploded in anger, we no longer think of ourselves as having evidence: we have an expression, manifestation, or display. And if these expressions, manifestations, and displays make up the class of disputed cases - note the way in which the disputed cases are introduced and their focus on expressive behaviour - then talk of evidence misrepresents the way in which we take ourselves to know the mind of another in the cases under dispute.

Austin appeals here to the way in which we report our knowledge of others' minds. We talk not only of knowing others' minds on the basis of symptoms or signs - twitches of eyebrows, clenchings of fists - but also on the basis of expressions, manifestations, and displays. And these notions are success notions: their corresponding verbs operate in much the same way as implicative verbs, presupposing that the subject is in the state which is expressed, manifested, or displayed. That is, the sentences 'Rahul expressed his anger', 'Rahul manifested his anger', and 'Rahul displayed his anger' each presuppose that Rahul was angry. This is relevant for Austin's claim because if we know that Rahul is angry on the basis of his expression of anger, and if his expression of anger entails that he is angry, then we know that he is angry on the basis of something which doesn't fall short in the way that evidence falls short. The grammatical function of terms like 'expression', 'manifestation', and 'display' supports the contention that we do not take that knowledge of others' minds which is based on expression, manifestation, and display to be knowledge based on evidence. ${ }^{25}$ This comprises Austin's support for the thought that the first claim is part of our ordinary thinking.

\section{Perception}

What about claim (2) - that our knowledge of others' minds is nonperceptual? Is it part of our ordinary ways of thinking? Many have thought it obvious that the claim that we know others' minds on the basis of

${ }^{25}$ This does not show that such knowledge is not based on evidence, anymore than the fact that we report our perceptual knowledge by means of factive constructions such as 'I saw the carpet' shows that our perceptual knowledge is non-evidential. Ayer makes much of this in his reply to Austin [Ayer 1967, pp.284-290], accepting that Austin is correct about the way in which we report our perceptual knowledge, but denying that anything interesting follows about the nature of perception. 
perception is contrary to common-sense. ${ }^{26}$ It can seem natural to think of other people's mental lives as hidden from view - a fact which I take to explain why a problem of other minds arises for us in a way that a problem of tables and chairs does not. It is this gap between the richness of our inner life and the poverty of our observable actions which Woolf traces in To the Lighthouse, and her characterisation of our interactions with one another suggests that our access to one another's mental lives cannot be perceptual. ${ }^{27}$ Yet defenders of a perceptual account have often claimed the reverse: not only that we know others' mental lives on the basis of perception, but that it is part of common-sense that our knowledge of others' minds is perceptual. ${ }^{28}$ How should we proceed when faced with such a stand-off?

On the face of it, there's something odd when parties to a debate disagree about which view should be considered part of the ordinary conception. Consider then the reasons why defenders of the perceptual account take their view to be part of common-sense. One prominent source of support consists in an appeal to the fact that we use a range of perceptual locutions when reporting our knowledge of others' emotional and phenomenal states: I see that Sushila is angry; Tobi looks tired. ${ }^{29}$ The felicity of these perceptual locutions resides in the fact to which Austin draws attention: that, at least in the set of cases under consideration, we come to know others' minds on the

${ }^{26}$ For two early examples, see [Price 1931, p.54; 1938, p.428]. If it takes seduction into philosophy to make it seem natural that our knowledge of others' minds is nonperceptual (cf. McDowell 1991, p.298), then - as Crispin Wright puts it - 'the seductive reach of philosophy is flatteringly wide' [2000, p.24].

${ }^{27}$ See [Nussbaum 1995, \$II], but cf. \$IV.

28 'We should not jib at, or interpret away, the common sense thought that... one can literally perceive, in another person's facial expression or his behaviour, that he is in pain...' [McDowell 1978, p. 136]; '[a way to] knowledge of other minds... is by looking (or listening, etc.) and probing. On this issue, philosophy can elucidate and vindicate the deliverances of common sense' [Green 2010, p.59; cf. 2007, pp.24-25]; 'it certainly seems to us as if we sometimes are perceptually aware of others' mental states' [Krueger and Overgaard 2012, p.248].

${ }^{29}$ Many are careful not to generalise beyond the case of our knowledge of emotions. Green, for instance, says that the claim that we can perceive 'such cognitive states as belief' is absurd [2007, p.92]. But cf. [McNeill 2015b] for some considerations motivating the perceptibility of some cognitive states. [Dretske 1973] contains a clear statement of the reasons for taking the perceptual view to be a part of common-sense. Opponents of the perceptual model likewise draw attention to the infelicity of perceptual locutions which take another's mental states as a direct object without qualifying it with reference to a piece of expressive behaviour. Consider: I saw Sushila's pain. McGinn [1985, p.123 fn.2] claims that sentences of this form 'seem definitely wrong'. Cassam [2007, pp.163-5] defends a perceptual model on which one can see that another person is angry without seeing her anger; compare [Dretske 1969, p.154]. 
basis of their expressive behaviour. I can see that Sushila is angry because she is expressing her anger; Tobi looks tired because her facial expression manifests her tiredness. It is the fact that expressions of mental phenomena play a role in our knowledge of others' minds which motivates the claim that the perceptual model is part of our ordinary thinking. ${ }^{30}$ So the question of whether the perceptual model is part of our ordinary ways of thinking turns on the implications of our taking expressions of mental phenomena to play a role in our knowledge of others' minds.

Let us accept that it is part of our ordinary conception that the expressions of mental phenomena are perceptible. And let us accept that in this class of disputed cases we take ourselves to know others' minds on the basis of their expressions of mentality. Do our ordinary ways of thinking thereby take such knowledge of others' minds to be perceptual? ${ }^{31}$ Answering this question requires us to say more about what is involved in knowing something on the basis of perception. So far I have confined myself to accounts of perceptual knowledge on which perception is a form of proof: one which settles the question by providing a basis for knowledge which is incompatible with the falsity of p. But this alone isn't enough to characterise a way of knowing as perceptual, at least so long as we are open to the thought that there may be ways of knowing which are neither evidential nor perceptual. What else is involved in coming to know something on the basis of perception?

Here is a schematic view of perceptual knowledge as we ordinarily conceive it. ${ }^{32}$ Perceptual knowledge involves the exercise of perceptual recognitional

\footnotetext{
${ }^{30}$ It is for this reason that so many of those who defend a perceptual account focus on expressions and expressive behaviour in setting out their views. See [Overgaard 2007], [Green 2007]. Compare Wittgenstein’s use of the term at $\$ 245$ of the Philosophical Investigations, and Cavell's discussion [1979, pp.341-344]. And note that the emphasis placed on expression by defenders of a perceptual account has long pedigree: see, for example, Price's objections to his opponents use of the term 'expressive' [1938, pp.451456].

${ }^{31}$ Some defenders of a perceptual account move very quickly from the perceptibility of the expressions of mental phenomena to the perceptibility of the phenomena themselves, but as Martin points out, commenting on a related claim in [Green 2007], it doesn't follow from the fact that expressions of emotions are perceptible, that emotions themselves are perceptible 'any more than saying that one sees his father in his face leads one to suppose that one sees the father when one sees the son' [Martin 2010a, p.82]. ${ }^{32}$ This draws on Austin's discussion of these issues [1949, pp.83-84] and, in particular, the account of perceptual knowledge that Alan Millar has presented and defended in a number of recent papers, especially his [2000] and [2010, pp.120-140]. Note that Millar takes his account to be an elucidation of 'common-sense thinking about perceptual knowledge' [2010, p.121]; Austin would claim likewise.
} 
capacities: capacities to recognise things on the basis of their appearance. There is coriander in the fridge. Coriander has a distinctive look. It has a distinctive look because there is a way it looks such that most things which have that look are bunches of coriander. I have the capacity to recognise coriander from the way it looks. And by exploiting my capacity to recognise coriander from the way it looks, I can come to know that there is coriander in the fridge. On this picture, perceptual knowledge has a subjective component and an objective component. On the objective side, there must be a distinctive way that things appear. And on the subjective side, subjects must be capable of exploiting that distinctive appearance to recognise how things stand. When both conditions are satisfied, subjects are in a position to exploit their recognitional capacities and gain knowledge of how things are from the way that things appear. ${ }^{33}$

Consider now two cases. The first is one in which I come to know that $o$ is $\mathrm{F}$ through perceptually discriminating $o$ and its Fness. Asha looks a certain way; there is a certain way that she looks when standing at the window of her office. Standing below her window, I exploit my capacity to recognise Asha on the basis of how she looks and come to know that Asha is in her office. This is a clear case of visual knowledge, knowledge of how things are on the basis of how things look. The second is a case in which I come to know that $o$ is $\mathrm{F}$ through perceptually discriminating something distinct from $o$ and its Fness. Sadiq always draws his curtains when he is working. His drawn curtains look a certain way. Standing below his window, I exploit my capacity to recognise his drawn curtains together with my knowledge that Sadiq always draws his curtains when he is working to come to know that Sadiq is in his office. How should we think of this knowledge?

One option is to treat such knowledge as evidential: after all, the grounds for the subject's judgement are compatible with the falsity of the judgement, for the curtains could be drawn even if Sadiq was not in his office. But an alternative is to take the drawn curtains to mean that Sadiq is in his office, where their meaning that Sadiq is in his office rules out the possibility that he might not be in his office. In this case, the drawn curtains provide a

\footnotetext{
${ }^{33}$ Millar defends this picture of perceptual knowledge at length in his [2010]. Various refinements are needed: it may be enough for an appearance to count as distinctive if it is an appearance that is had by most things around here [Millar 2010, p.126]; or it may be required for an appearance to be distinctive that the object appears to be a certain way because it is that way [Smith 2013, p.13]. I put these complications to one side.
} 
subject with proof that Sadiq is in his office and we can think of the resulting knowledge as perceptual. ${ }^{34} \mathrm{~A}$ full account of perceptual knowledge would need to decide between these options but we need not to do so here. For our purposes, what is important is that even if one is inclined to treat such cases as instances of perceptual knowledge, they are importantly different from paradigmatic cases of perceptual knowledge, since the knowledge in question is based on discriminating a state of affairs which is distinct from the fact known.

This distinction matters because those who claim that it is part of our ordinary thinking that our knowledge of others' minds is perceptual take it that our knowledge of others' minds is a paradigm case of perceptual knowledge, on a par with our perceptual knowledge of ordinary material objects. But even if we grant them that it is part of ordinary thinking that our knowledge of others' minds, in the disputed cases, is based on others' expressive behaviour, this doesn't show that we take such knowledge to be paradigmatically perceptual. For there are two different ways in which our knowledge of others' minds might be based on others' expressive behaviour. Consider the knowledge that Sushila is angry. It may be that I come to know that Sushila is angry through possessing the capacity to recognise her being angry on the basis of her expression of anger. Or it may be that I come to know that Sushila is angry through possessing the capacity to recognise her expression of anger on the basis of how the expression looks. If ordinary thinking assumes the first option, then we straightforwardly treat our knowledge of others' minds as perceptual. If ordinary thinking assumes the second, then things are much less clear.

The issue here concerns how we think about expressions of mentality, their relation to mental phenomena, and the kinds of recognitional capacities exercised in our gaining knowledge of others' minds. And it seems to me that our ordinary ways of thinking take our knowledge of others' minds to be mediated by other people's expressive behaviour in a way that we do not take paradigmatic cases of perceptual knowledge to be mediated by the distinctive appearances of the objects of perceptual knowledge. Consider again a paradigmatic case of perceptual knowledge. I know that there is coriander in the fridge through exploiting my capacity to recognise

\footnotetext{
${ }^{34}$ This option is suggested by Travis [2005, pp.301-305]. I have tried to phrase the view so as to indicate its connection to Travis's views about the occasion-sensitivity of meaning.
} 
coriander on the basis of how it looks. If we are to find a parallel in our knowledge of others' minds, it would have to be the case that I come to know that Sushila is angry through exploiting my capacity to recognise her anger on the basis of its expression. If this were the role played by mental expressions, then there would be grounds for taking it to be part of common-sense that our knowledge of others' minds is perceptual.

But this mischaracterises the role that expressions play in our knowledge of others' minds. Knowledge of others' minds is mediated by others' expressive behaviour: I come to know that Sushila is angry through exploiting my capacity to recognise her expression of anger, in the same way that I might come to know that Sadiq is in his office through exploiting my capacity to recognise his curtains being drawn. On this way of thinking about the expressions of mentality, my knowledge that Sushila is angry is not paradigmatically perceptual since it exploits not my capacity to recognise anger but my capacity to recognise something which appears distinct from anger, namely its expression. Our knowledge of others' minds is mediated in a way that our paradigmatic perceptual knowledge is not.

The mediate nature of our knowledge of others' minds is implicit in the idea that we perceive mental states by seeing their expression. ${ }^{35}$ And it is built into the delimitation of the class of disputed cases: we fix upon the class in question by specifying those cases in which I come to know another's mental state by perceiving some piece of expressive behaviour. But the use of this 'by' locution indicates that we do not treat expressions of mentality on a par with the distinctive appearances of the objects of perceptual knowledge. When we know that the floor is dirty on the basis of how it looks, we do not claim to know it by seeing its appearance: we talk simply of seeing the dirty floor. But we do talk of knowing that Sushila is angry by seeing her expression of anger. This suggests that we ordinarily take the role of expressions in our knowledge of other minds to differ from role played by the appearances of objects in paradigm cases of perceptual knowledge. And this shows how we can accept, with the perceptual theorist, that ordinary thinking takes the expressions of mentality to be perceptible, whilst denying that we ordinarily take our knowledge of others' minds to be perceptual. It is part of common-sense that expressions of mentality are perceptible, and that we come to know others' minds on the basis of those expressions. But

35 This formulation is used often by defenders of a perceptual account. See, e.g., [Cassam 2007, p.165; Green 2007, p.89; Krueger 2012, p.151]. 
the mediated nature of our knowledge of others' minds explains why we treat it as differing from paradigmatic cases of perceptual knowledge in an important and straightforward way.

This line of thought raises a number of questions about the nature of expressions of mentality and their relation to mental phenomena themselves. I will take up some of these in the final section. For now, we can settle with the thought that our ordinary ways of thinking treat our knowledge of others' minds as grounded in a capacity to recognise expressions of mentality rather than a capacity to recognise mental phenomena themselves, and that this is reflected in the way we take expressions of mentality to mediate our knowledge of others' minds in a way that we don't take the appearances of objects to mediate our knowledge of empirical things. I take this to show that we ordinarily treat our knowledge of others' minds as importantly different from paradigm cases of perceptual knowledge, in a way which would explain why (2) is part of common-sense.

There is one further thought which has dialectical purchase against some who take the negation of (2) to be part of common-sense. Remember that our starting point is Lily's predicament: a situation where we know p, indeed, we know that we know p, and yet we do not know how we know that we know p. This combination of claims should seem decidedly odd if our knowledge that $\mathrm{p}$ were based in perception. For in paradigmatic cases of perceptual knowledge, it is transparent to us how we come to know the fact in question. The first letter of this paragraph is ' $T$ '. You can come to know this through exercising your perceptual capacities. And you know how you know this - you can see that this is the case. ${ }^{36}$

I'm tempted by the claim that all instances of perceptual knowledge are like this: that if one knows p, right now, on the basis of perception, then one knows how one knows that $\mathrm{p}$. This claim needs finessing in various ways, but the crucial point is that this claim is accepted by some who hold that the negation of (2) is part of common-sense. ${ }^{37}$ And if this claim holds, and we come to know others' minds on the basis of perception, then it should

\footnotetext{
${ }^{36}$ See [Martin 2005, p.701] for an expression of this thought about perception.

${ }^{37}$ I have in mind McDowell: see his [2011] for the claim that perception is a form of selfconscious awareness. An instance: 'A rational perceptual capacity is a capacity not only to know certain kinds of thing about the environment but, on an occasion on which one knows something of the relevant kind through the exercise of the capacity in question, to know that that is how one knows it.' [2011, p.41]. See [2011, pp.41-53] for further details.
} 
be transparent to us that we know others' minds on the basis of perception. But Lily's question shows us that it is often not so transparent. So we don't take ourselves to know on the basis of perception.

This consideration has dialectical rather than substantive force, since most will deny the luminosity of our knowledge that we know on the basis of perception. ${ }^{38}$ So let me mention one final interpretative consideration in support of the claim that (1) and (2) are part of common-sense. When one looks at the history of philosophical thinking about others' minds, it is striking that those writing on this topic disagree not only about whether our knowledge of others' minds is perceptual or inferential but also about which of these views is part of common-sense. How can we make sense of this dispute?

Taking both (1) and (2) to be part of our ordinary thinking offers a straightforward explanation: those who claim that the perceptual view is part of common-sense are tracking the genuine observation that we take our knowledge of others' minds to be non-evidential; those who claim that the inferential view is part of common-sense are tracking the genuine observation that we take our knowledge of others' minds to be nonperceptual. In both cases, the claims about common-sense are prompted by the recognition of a genuine feature of our ordinary ways of thinking in combination with a philosophical assumption about the nature of our knowledge of others' minds. The apparent dispute about our ordinary conception lies not in differing views about our ordinary conception but in the shared substantive claim that our knowledge of others' minds is either evidential or perceptual. It is this philosophical claim which leads to the appearance of dispute.

\footnotetext{
${ }^{38}$ Since the claim in question - if one currently knows $\mathrm{p}$ on the basis of perception, then one knows that one knows $\mathrm{p}$ on the basis of perception - is a form of a KK principle, one might think it subject to Williamson's anti-luminosity argument [2000, ch.4]. Whether this is so will depend on how we are to understand the relation between one's knowledge that $\mathrm{p}$ and one's knowledge that one knows $\mathrm{p}$ on the basis of perception. McDowell takes the relation to be constitutive: 'A bit of rational perceptual knowledge includes knowledge that it is through perception that one knows whatever it is that one knows about the environment' [2011, pp.41-42]. And some have claimed that Williamson's argument fails in cases where there is a constitutive connection between the luminous state and a subject's belief that she is in that state. See [Berker pp.17-19].
} 


\section{Expressive Knowledge}

This brings us back to Lily's question. Rejecting the claim that our knowledge of others' minds is either evidential or perceptual clears our ordinary conception of inconsistency. But it replaces it with confusion. For how can there be a way of knowing which is neither evidential nor perceptual? Defenders of a perceptual account are right to note that we take our knowledge of others' minds to be based on others' expressive behaviour. But we don't think of expressions of mentality as providing mere evidence for the presence of mental states; and nor do we treat them as comparable to the appearances of material objects, enabling our perceptual knowledge of others' mental lives. So how should we think of the relation between expressions of mentality and mental phenomena? It is this question which, I think, takes us to the heart of why we find answering Lily's question so difficult. We think of our knowledge of others' minds as not based on evidence; we think of our knowledge of others' minds as not based on perception. These are purely negative characterisations of such knowledge. But answering Lily's question requires us to say more. And this is where we fall silent.

Say one buys this diagnosis. How does it affect what we, as theorists, should say about our knowledge of others' minds? How does this account of our ordinary ways of thinking bear on the philosophical project of answering Lily's question? There are three ways we could react to the story I've provided.

First, one might think that our knowledge of others' minds really is evidential, despite the fact that we ordinarily take such knowledge to be nonevidential. In this case, I suggest, we are owed an explanation of why we take such knowledge to be non-evidential when it really is based on evidence. There are a number of forms such an explanation could take: perhaps the inference from evidence to judgement is immediate or unconscious, and we are apt to overlook such inferences; perhaps our beliefs only count as knowledge in virtue of our being able to engage in a process of inferential reasoning, even if it is true that we don't actually do so. ${ }^{39}$ It is noticeable that extant evidential accounts do undertake to provide such an explanation: we

${ }^{39}$ See [Price 1931, pp.56-57] for two versions of the first response, and [Broad 1925, p.324, pp.335-347] for the second. Ayer makes much the same point with regards to our perceptual knowledge of material objects in his response to Austin [Ayer 1967, pp.284290]. 
know others' minds on the basis of evidence and our reluctance to recognise it as such shows only that the inferential transition between evidence and judgement is immediate and unconscious.

Second, one might think that our knowledge of others' minds really is perceptual, despite the fact that we ordinarily take such knowledge to be non-perceptual. Again, I suggest, that, if this is the case, we are owed an explanation of why we take such knowledge to be non-perceptual when it is really based on perception. Extant perceptual accounts typically do not undertake to provide such an explanation, presumably since their defenders deny that it is true that we take such knowledge to be non-perceptual. But if the line of thought above is plausible, then some explanation should be provided.

Here is one form an explanation could take. I claimed above that we ordinarily treat expressions of mentality as operating differently from the appearances of objects, in a way that prescinds a straightforward amalgamation of knowledge of others' minds to perceptual knowledge. Nevertheless, one might think that this differential treatment is mistaken. Expressions of mentality function exactly like the appearances of objects and our knowledge of others' minds is gained through perceptually recognising mental phenomena on the basis of their expression and we are wrong to treat them differently. Why, then, do we treat them so?

One explanation is that our concern is the knowledge of human beings. As intentional agents, human beings are capable of altering the ways in which their mental states are presented: they can feign expressive behaviour even when there is no mental item to be expressed. In this, they differ from the non-minded parts of the external world which don't, as a rule, change their appearance with the purpose of deceiving us. And pragmatic social and ethical considerations may make this gap particularly salient to us: it matters to us if we are deceived by or misunderstand another. As Austin puts it, 'we may be deceived by the appearance of an oasis, or misinterpret the signs of the weather, but the oasis cannot lie to us and we cannot misunderstand the storm in the way we misunderstand the man' [1946, p.112]. One might think, then, that there are pragmatic and social pressures which explain our treating expressions differently from appearances, even though both function in the same way and even though we can use expressions to gain 
perceptual knowledge of others' minds much as we use appearances to gain perceptual knowledge of the world. ${ }^{40}$

These options are revisionary responses to Lily's question: they each explain away some aspect of our ordinary ways of thinking about other minds. A third option would be to take our ordinary conception of knowledge of others' minds at face-value: to hold that we have a non-evidential and nonperceptual way of knowing about other minds. In virtue of being nonevidential, such a way of knowing would have to be a form of proof: a way of knowing which doesn't fall short of what is known in the way that evidence falls short. But in virtue of being non-perceptual, it would not provide us with proof by exploiting perceptual recognitional capacities to discriminate others' mental lives.

One way to take this option would be to identify our way of knowing about others' minds with some particular non-perceptual, non-evidential way of knowing. Some have suggested, for example, that knowledge gained through testimony is neither based on evidence nor based on perception and one might thus try to account for our knowledge of others' minds in terms of the things that other people tell us. ${ }^{41}$ Alternatively, one might hold that we have a basic, non-perceptual, and non-evidential way of knowing others' minds. In this final part of this paper I'll sketch one form this might take. I'll suggest that our knowledge of others' minds is a form of expressive knowledge. Expressive knowledge is knowledge gained on the basis of others' expressions of mentality. As I shall elaborate it, expressive knowledge is neither evidential nor obviously perceptual. It is a distinctive way we have of knowing about the social world, one which exploits a capacity to discriminate expressive behaviour. My presentation of this proposal will be

\footnotetext{
${ }^{40}$ One might read this response into the final paragraphs of Austin's 'Other Minds', in effect reading Austin as defending a perceptual account of our knowledge of others' minds but noting that there are possibilities, including deception, which are relevant to our knowing about others' minds but not relevant to our knowing about other aspects of the material world. Against this reading, I think it is noteworthy that Austin doesn't use the kinds of perceptual locutions in characterising our knowledge of others' minds that one finds in McDowell, for example.

${ }^{41}$ See [Gomes 2014] for some initial considerations on testimony and its role in allowing knowledge of others' minds. The possibility of knowing about others' minds through testimony features centrally in Austin's 'Other Minds'.
} 
necessarily select, but I hope it will provide some indication of how one might take the non-reductive option seriously. ${ }^{42}$

Expressive knowledge, I have said, is knowledge gained on the basis of others' expressions of mentality. We can flesh out this initial characterisation and understand its contrast with perceptual and evidential knowledge by addressing two topics. First, the nature of expressions and their relation to mental phenomena. Second, the kind of capacities needed to discriminate expressions and exploit that recognition to gain knowledge of others' mental lives.

Start with expressions. I argued above that we don't ordinarily take the relation between expressions and mental phenomena to be evidential. The distinction between evidence and proof concerns the modal status of one's ground for belief. When one has evidence for a proposition, one's grounds are compatible with it not being the case that p; whereas when one has proof, one's grounds exclude the possibility of $\mathrm{p}$ not being so. Thus, if knowledge based on expressions is to be a form of proof, expressions must exclude the falsity of what one comes to know on their basis.

What account of expressions fits this characterisation? At the very least, expressions must bear a necessary connection to the mental phenomena that they express, such that whenever one has the former, then one has the latter. Only so will they be incompatible with the falsity of what one comes to know on their basis. This raises an immediate worry: isn't it possible for there to be an expression of mentality without the presence of the mental phenomenon in question, as in the case of the perfect actor? The account of expressive knowledge as proof must hold that this is not possible and thus must endorse a disjunctive or non-conjunctive account of the commonality between genuine expressions of mentality and mere expressive behaviour. This is not an ad hoc response but flows naturally out of our ordinary commitments to the way expressions mediate our knowledge of others' minds. I suggested above that we take our recognitional capacities to track expressions themselves, and this explains, in part, our commitment to such knowledge being mediated. But if our recognitional capacities track expressions themselves, this suggests that they have an appearance, one that

\footnotetext{
42 The proposal has important connections to the criterial view associated with Wittgenstein's discussion of these issues in the later writings. See [Witherspoon 2011] for an overview of Wittgenstein's views and a discussion of some of the interpretative issues.
} 
can be mimicked. And just as mimicking the appearance of a tomato is not sufficient for producing a tomato, so too is the mimicking of the appearance of an expression not sufficient for the production of an expression. Expression is one thing; mere expressive behaviour another.

What kind of relation guarantees a necessary connection between expressions and mental phenomena? A second concern is that the natural candidates for such a relation - identity, constitution, part-whole relations - have all been used by perceptual theorists to characterise the relation between expressions and mental phenomena, and one might worry that an account of expressive knowledge which makes use of such relations will collapse into a perceptual account. Perhaps this is true if the relation between expressions and mental phenomena is identity, but for necessary relations which fall short of identity it doesn't follow in general that if one is perceptually aware of $F$ and $F$ is necessarily related to $G$ then one is perceptually aware of $G$; nor does it follow in general that if one knows that $F$ is the case on the basis of perception, and $F$ is necessarily related to $G$, then one knows that $G$ is the case on the basis of perception. So the mere presence of a necessary connection doesn't entail that knowledge based on expressions is perceptual.

Nevertheless, even if it does not entail that the knowledge based on expressions is perceptual, we need to know more about which necessary connection holds between expressions and mental phenomena before we can be confident that knowledge based on expressions is non-perceptual. In very broad terms, we can think of the relation in question as one of metaphysical dependence, since metaphysical dependence entails the kind of modal profile in question. But metaphysical dependence is stronger than a mere modal connection, since two items can necessarily covary without one holding in virtue of the other. And whilst relations such as constitution and proper parthood secure metaphysical dependence through a denial of the genuine distinctness of one or other aspect of the relata, this is not required: distinct existences can be related by relations of metaphysical dependence. ${ }^{43}$

\footnotetext{
43 See [Steward 1997, p.72f], [Soteriou 2007, pp.551f] and [Fine 2012, pp.38-39] for discussion. [Parrott 2017] makes a related suggestion concerning the relation between expressions and mental phenomena; the proposal may be one way of spelling out Austin's claims about the relations between emotions and their natural expressions; see [Austin 1946, p.108f].
} 
When this relation of metaphysical dependence holds, I will say that the expression obtains in virtue of the mental phenomenon in question. The modal nature of this relation secures the non-evidential nature of expressive knowledge. But why should we think of knowledge gained on the basis of expressions as non-perceptual? The answer to this question turns on the ways in which our recognitional capacities are operative in the production of expressive knowledge. I argued above that we ordinarily take our recognitional capacities to track expressions of mentality on the basis of their appearances, rather than taking our recognitional capacities to target mental phemomena themselves on the basis of their appearance. This marks a difference between expressive knowledge and paradigmatic cases of perceptual knowledge. The recognitional capacities involved in expressive knowledge are not capacities to discriminate other people's mental states: they are capacities to discriminate expressive behaviour, something which is distinct from mental phenomena themselves. If this claim can be defended, we can see why expressive knowledge should be classed as non-perceptual

Can the claim be defended? In order to do so, we need to make plausible that the recognitional capacities involved in our knowledge of others' minds track the expressions of mental phenomena rather than the phenomena themselves; and, conversely, that the recognitional capacities involved in our knowledge of others' minds track expressions of mental phenomena rather than mere expressive behaviour, the kind of behaviour which doesn't allow proof of mental phenomena. Facts about which capacities a subject possesses can be understood as determined partly in terms of the range of situations in which subjects can exercise those capacities, and partly in terms of the situations which explain the possession of such capacities. I suspect that attention to the genealogy of the recognitional capacities involved in our knowledge of others' minds will make plausible the claim that our recognitional capacities track expressions of mental phenomena rather than the phenomena themselves, but this is a task for elsewhere. It is attention to these issues which will determine whether expressive knowledge is not perceptual in any sense of the term.

Still, we have the outlines of a stable response to Lily's question. Expressive knowledge differs from paradigmatic cases of perceptual and evidential knowledge because in cases of expressive knowledge, our knowledge of other people's mental lives is mediated by their expressive behaviour in a way that reflects a capacity to track expressive behaviours themselves on the basis of their distinctive appearances; and our capacities to track expressive 
behaviour afford us a proof of the presence of other people's mental lives in a way that mere behavioural evidence of mentality would not.

I think there is much to recommend this way of thinking about others' minds. Most significantly, treating expressive knowledge as distinct in kind from paradigmatic cases of perceptual and evidential knowledge allows us to recognise a distinctive source of knowledge of the social world: Lily's question is answered when we recognise the distinctive role that expressions play in our knowledge of others' minds. ${ }^{44}$

Let me conclude with another quote from Woolf, this time from Jacob's Room. This is the quote that ends John Wisdom's contribution to the symposium at the 1946 Joint Session of the Mind Association and the Aristotelian Society at which he, Austin, and Ayer presented their papers on our knowledge of others' minds. The quote is long, and I only reproduce part of it here:

Let us consider letters- - how they come at breakfast, and at night, \with their yellow stamps and their green stamps, immortalized by the postmark - for to see one's own letter on another's table is to realize囚how soon deeds sever and become alien. Then at last the power of the mind to quit the body is manifest, and perhaps we fear or hate or wish annihilated this phantom of ourselves, lying on the table...

Life would split asunder without them... And the notes accumulate. And the telephones ring. And everywhere we go wires and tubes surround us to carry the voices that try to penetrate before the last card is dealt and the days are over. 'Try to penetrate,' for as we lift the cup, shake the hand, express the hope, something whispers, Is this all? Can I never know, share, be certain? Am I doomed all my days to write letters, send voices,

\footnotetext{
${ }^{44}$ A topic which I don't have space to address here concerns the relation between the capacities involved in gaining expressive knowledge and the first-personal capacities we have to express our own mental states. If it could be made plausible that the former depend in some way on the latter, then our having a certain kind of self-conscious capacity for knowing about our own minds would have explanatory priority in explaining our capacity to know about other people's minds without the latter reducing to some more basic way of knowing about the material world. This bears on the presentation of self-knowledge in some of Richard Moran's influential writings where the difference between self-knowledge and knowledge of others' minds is characterised by the distinction between a distinctive first-personal way of knowing one's own mind and knowledge which is based on 'evidence or observation' [2001, p.xxix]. It seems to me one could accept Moran characterisation of the way in which we know our own mind without treating our knowledge of others' minds as any less distinctive - and, indeed, that recognising the role of expressive knowledge in our knowledge of others' minds may illuminate what is distinctive about our self-knowledge.
} 
which fall upon the tea-table, fade upon the passage, make appointments, while life dwindles, to come and dine? [Jacob's Room: pp.124-125]

Wisdom takes this passage as highlighting an isolation which we may defeat but cannot vanquish [1946, p.147], an isolation which finds voice in the problem of other minds. But it also showcases a way of thinking about letters as both instances of the mind, phantoms of ourselves, and yet distinct from and requiring penetration to the intentions with which they were made. Woolf's metaphor might be used to showcase a way of thinking about expressive behaviour more generally: as both an instance of the mind, a phantom of ourselves, and yet at one remove.

The suggestion of this essay is that this way of thinking about letters captures something of our ordinary ways of thinking about our knowledge of others' minds. We do not think of other people's expressive behaviour as falling short of their minds in the way that evidence falls short of that which it indicates. But neither do we think of it as allowing perceptual contact with another's mental life. And it is this character of ordinary thinking which leaves us at a loss when trying to answer Lily's question: how do we know? The problem of other minds cannot be satisfactorily exorcised until we face up to this tension in our ordinary thinking. The recognition of expressive knowledge as a way of knowing which is both non-perceptual and nonevidential offers us a route to explaining how this aspect of ordinary thinking can be made sensible. ${ }^{45}$

${ }^{45}$ This paper was first presented at a conference on the problem of other minds held at St Hilda's College, Oxford in March 2013. My thanks to Anita Avramides and Michael Sollberger for organising that conference, and to those present for the discussion. My thanks also to audiences in Oxford, Bochum, Manchester, and Warwick, and to the LonOx discussants, for incredibly helpful questions and comments. Finally, thanks to Anita Avramides, Craig French, Guy Longworth, Søren Overgaard, and, especially, Matt Parrott for discussion and written comments. 


\section{References}

Austin, J. L. 1962. Sense and Sensibilia. Oxford: Oxford University Press.

Austin, J.L. 1946. Other Minds. Reprinted in his Philosophical Papers, pp.76-116. Oxford: Oxford University Press, 1961.

Ayer, A.J. 1956. The Problem of Knowledge. London: Macmillan

Ayer, A.J. 1967. Has Austin refuted sense-data? Reprinted in K.T. Fann (ed.)

Symposium on J.L. Austin. New York: Humanities Press.

Berker, S. 2008. Luminosity Regained. Philosophers' Imprint 8 (2):1-22.

Boghossian, P. 1989. Content and self-knowledge. Philosophical Topics 17 (1):5-26.

Broad, C.D. 1925. The Mind and its Place in Nature. London: Routledge and Kegan Paul.

Buras, T. 2002. The problem with Reid's direct realism. Philosophical Quarterly 52 (209):457-477.

Cassam, Q. 2007. The Possibility of Knowledge. Oxford: Oxford University Press.

Cavell, S. 1979. The Claim of Reason: Wittgenstein, Skepticism, Morality, and Tragedy. Oxford: Oxford University Press.

Davidson, D. 1991. What is Present to the Mind?. Philosophical Issues 1:197-213.

Dretske, F. 1969. Seeing And Knowing. Chicago: University Of Chicago Press.

Dretske, F. 1973. Perception and Other Minds. Noûs 7:34-44

Duddington, N.A. 1918. Our Knowledge of Other Minds. Proceedings of the Aristotelian Society, 19:147-178.

Fine, K. 2012. Guide to ground. In F. Correia \& B. Schnieder (eds.), Metaphysical Grounding. Cambridge: Cambridge University Press.

Gomes, A. 2011. Is There a Problem of Other Minds?. Proceedings of the Aristotelian Society_111:353-373.

Gomes, A. 2014. Testimony and Other Minds. Erkenntnis. doi: $10.1007 / \mathrm{s} 10670-014-9619-8$

Gomes, A. Forthcoming. Skepticism and Other Minds. To appear in D. Machuca \& B. Reed (eds.), Skepticism: From Antiquity to the Present. London: Bloomsbury.

Gopnik, A. \& Wellman, H. 1992. Why the Child's Theory of Mind Really Is A Theory. Mind \& Language 7:145-171.

Green, M. 2007. Self-Expression. Oxford: Oxford University Press.

Green, M. 2010. Perceiving Emotions. Proceedings of the Aristotelian Society, Supplementary Volume 84:45-61.

Hacking, I. 1975. The Emergence of Probability. Cambridge: Cambridge University Press.

Hampshire, S. 1969. Some Difficulties in Knowing. Reprinted in T. Honderich and M. Burnyeat. (eds.) Philosophy As it Is. Harmondsworth: Penguin, 1979. 
Hatfield, G. 2002. Perception as Unconscious Inference. In D. Heyer (ed.), Perception and the Physical World: Psychological and Philosophical Issues in Perception. New York: Wiley.

Hinton, J.M. 1973. Experiences: An Inquiry Into Some Ambiguities. Oxford: Clarendon Press.

Kalderon, M. \& Travis, C. 2013. Oxford Realism. In M. Beaney (ed.) The Oxford Handbook of the History of Analytic Philosophy. Oxford: Oxford University Press. 489--517.

Kelly, T. 2014. Evidence. Stanford Encyclopedia of Philosophy.

Krueger, J. \& Overgaard, S. 2012. Seeing subjectivity: Defending a perceptual account of other minds. ProtoSociology: Consciousness and Subjectivity $47: 239-262$.

Krueger, J. 2012. Seeing Mind in Action. Phenomenology and the Cognitive Sciences 11 (2): 149-73.

Martin, M.G.F. 2002. The transparency of experience. Mind and Language 4 (4):376-425.

Martin, M.G.F. 2005. Perception. In F. Jackson \& M. Smith (eds.) The Oxford Handbook of Contemporary Philosophy. Oxford: Oxford University Press.

Martin, M.G.F. 2010a. Getting on Top of Oneself: Comments on SelfExpression. Acta Analytica, 25 (1): 81-88.

Martin, M.G.F. 2010b. What's in a look? In B. Nanay (ed.) Perceiving the World. Oxford: Oxford University Press. 160-225.

McDowell, J. 1982. Criteria, Defeasibility and Knowledge. Reprinted in his Meaning, Knowledge and Reality, pp.369-94. Cambridge MA: Harvard University Press, 1998.

McDowell, J. 1991. Intentionality and interiority in Wittgenstein. Reprinted in his Mind, Value and Reality, pp.297-324. Cambridge MA: Harvard University Press, 1998.

McDowell, J. 2011. Perception as a Capacity for Knowledge. Marquette University Press.

McGinn, C. 1984. What is the Problem of Other Minds?. Proceedings of the Aristotelian Society Supplementary Volume 58:119-137.

McGinn, M. 1998. The Real Problem of Others: Cavell, Merleau-Ponty and Wittgenstein on Scepticism about Other Minds. European Journal of Philosophy 6(1): 45-58.

McNeill, W.E.S. 2012. On Seeing That Someone is Angry. European Journal of Philosophy 20: 575-597.

McNeill, W.E.S. 2015a. Inferentialism and Our Knowledge of Others' Minds. Philosophical Studies 172:1435-1454.

McNeill, W.E.S. 2015b. Seeing What You Want. Consciousness and Cognition 36(C): 554-564.

Michael, J., \& De Bruin, L. 2015. How direct is social perception?. Consciousness and Cognition 36(C): 373-375. 
Mill, J.S. 1865. An Examination of Sir William Hamilton's Philosophy, Collected Works of John Stuart Mill Volume IX, ed. J.M. Robson and A. Ryan. Toronto: University of Toronto Press, 1979.

Millar, A. 2000. The scope of perceptual knowledge. Philosophy 75 (291):73-88.

Millar, A. 2010. With D. Pritchard \& A. Haddock. The Nature and Value of Knowledge: Three Investigations. Oxford: Oxford University Press.

Moran, R. 2011. Authority and Estrangement: An Essay in Self-Knowledge. Princeton, NJ: Princeton University Press.

Nichols, S. \& Stich, S. 2003. Mindreading: An Integrated Account of Pretence, Self- Awareness, and Understanding Other Minds. Oxford: Oxford University Press.

Nussbaum, M. C. 1995. The window: knowledge of other minds in Virginia Woolf's To the Lighthouse. New Literary History 26(4): 731-753.

Overgaard, S. 2007. Wittgenstein and Other Minds: Rethinking Subjectivity and Intersubjectivity with Wittgenstein, Levinas, and Husserl. London: Routledge.

Parrott, M. 2017. The Look of Another Mind. Mind 126: 1023-1061.

Price, H.H. 1931. Our knowledge of other minds. Proceedings of the Aristotelian Society 32: 53-78

Price, H.H. 1938. Our evidence for the existence of other minds. Philosophy 13 (52):425-56.

Prichard, H. A. 1919. Professor John Cook Wilson. Mind, 28 (111):297318.

Reid, T. 1764. An Inquiry into the Human Mind on the Principles of Common Sense. Reprinted in Inquiry and Essays, ed. R. Beanblossom and K. Lehrer. Indianapolis: Hackett Publishing. 1983.

Reid, T. 1785. Essays on the Intellectual Powers of Man. Reprinted in Inquiry and Essays, ed. R. Beanblossom and K. Lehrer. Indianapolis: Hackett Publishing. 1983.

Robbins, J, and Rumsey, A. 2008. Anthropology and the Opacity of Other Minds. Anthropological Quarterly 81 (2):

Smith, J. 2010. Seeing Other People. Philosophy and Phenomenological Research 81 (3): 731-748.

Smith, J. 2013. The Phenomenology of Face-to-Face Mindreading. Philosophy and Phenomenological Research. doi: 10.1111/phpr.12063.

Soteriou, M. 2007. Content and the stream of consciousness. Philosophical Perspectives 21: 543-568.

Spaulding, S. 2015. On Direct Social Perception. Consciousness and Cognition, 36(C): 472-482.

Steward, H. 1997. The Ontology of Mind: Events, Processes, and States. Oxford: Clarendon Press.

Thomas, J. 2001. Mill's Argument for Other Minds. British Journal for the History of Philosophy 9:507-523.

Travis, C. 2005. A sense of occasion. Reprinted in his Occasion-Sensitivity, pp.290-315. Oxford: Oxford University Press, 2008. 
Travis, C. 2013. Perception: Essays After Frege. Oxford: Oxford University Press.

Williamson, T. 2000. Knowledge and Its Limits. Oxford: Oxford University Press.

Wisdom, J. 1946. Other minds. Proceedings of the Aristotelian Society Supplementary Volume 20 (194):122-47.

Witherspoon, E. 2011. Wittgenstein on Criteria and The Problem Of Other Minds. In O. Kuusela \& M. McGinn (eds.) The Oxford Handbook of Wittgenstein. Oxford: Oxford University Press.

Wittgenstein, L. 1953. Philosophical Investigations. Oxford: Basil Blackwell.

Wittgenstein, L. 1992. Last Writings on the Philosophy of Psychology. Vol. 2: The Inner and the Outer. Oxford: Blackwell.

Woolf, V. 1922. Jacob's Room. Reissued by Oxford: Oxford University Press, 1992.

Woolf, V. 1927. To the Lighthouse. Reissued by London: Penguin Books, 2011.

Wright, C. 2000. Self-knowledge: The Wittgensteinian legacy. In C. Wright, B. Smith \& C. Macdonald (eds.) Knowing Our Own Minds. Oxford: Oxford University Press. 